\title{
Occupational absorption of tellurium: a report of two cases
}

\author{
E. S. BLACKADDER and W. G. MANDERSON \\ Employment Medical Advisory Service, Portcullis House, India Street, Glasgow and \\ the Royal Infirmary, Glasgow
}

\begin{abstract}
Blackadder, E. S., and Manderson, W. G. (1975). British Journal of Industrial Medicine, 32, 59-61. Occupational absorption of tellurium: a report of two cases. Industrial uses of tellurium are limited, and reported cases of tellurium absorption of occupational origin are rare. Two such cases are reported here. Both showed typical signs and symptoms of intoxication; in particular, the stench of sour garlic was noted on breath and from excreta. An unusual feature was the bluish-black discoloration of the webs of the fingers and streaks on the face and neck. Full hospital investigation was negative. No permanent damage resulted and each patient made a spontaneous recovery without treatment.
\end{abstract}

Tellurium ( $\mathrm{Te}$ ) is a heavy element exhibiting the physical properties and silvery-grey lustre of a metal and the chemical properties of a non-metal such as sulphur. Selenium (Se) is similar. Both are found in the anode sludge of copper refining and have identical physiological effects with the exception that $\mathrm{Te}$ inhibits sweating and Se does not. Tellurium has a limited number of industrial uses:

in the vulcanizing of rubber, where it increases resistance to heat, abrasion, and ageing;

in bacteriology, as the tellurite diagnostic test for diphtheria;

as an additive to cast iron, steel, and copper, to improve machinability and improve surface resistance to wear and corrosion;

as a colouring agent in the glass industry;

as a catalyst in the chemical industry.

Formerly therapeutic uses were as a sedative, in the treatment of syphilis, and to reduce night sweats in phthisis.

No fatality and no severe injury has been reported from occupational exposure. Accidental injection of sodium tellurite in place of sodium iodide in retrograde pyelography resulted in two deaths in a military hospital in 1944 (Keall, Martin, and Tunbridge, 1946). Reports of cases of occupational tellurium poisoning are rare (Shie and Deeds, 1920;
Steinberg, Massari, Miner, and Rink, 1942; Amdur, 1947). Nevertheless tellurium is recognized as a potential industrial hazard, and the threshold limit value has been agreed in the UK and USA at $0.1 \mathrm{mg} / \mathrm{m}^{3}$, and in the USSR the maximum allowable concentration is $0.01 \mathrm{mg} / \mathrm{m}^{3}$.

Absorption is mainly by inhalation, although cases are recorded of intoxication from ingestion of solutions of tellurium (Duckett, 1970). Certain esters of tellurium are absorbed through intact skin. Excretion is slow, mainly renal and to a lesser extent pulmonary, and therefore Te tends to accumulate in the body, especially in the kidneys and liver (Vignoli and Defretin, 1964).

\section{Case reports}

Two male postgraduates were engaged in research on the industrial and therapeutic uses of tellurium esters. Accidental exposure to tellurium hexafluoride gas occurred when $50 \mathrm{~g}$ leaked from a cylinder in a small laboratory.

Case 1 aged 24 years experienced a metallic taste in the mouth and had the characteristic pungent odour of sour garlic in his breath and to a lesser degree in the sweat and urine. There was some anorexia but no vomiting nor constipation. However, he complained most of tiredness, tending to fall asleep in the late afternoon or evening. He was admitted to hospital for three days' observation and 
investigation. There was no dry skin nor itch, but two days after admission he developed an erythematous papular vesicular rash on the hands, arms, and neck. An interesting and unusual feature of this case was that he exhibited bluish-black patches in the webs of the fingers and, to a lesser degree, in streaks on the neck and face (Figure). These took several weeks to fade.

Case 2 aged 26 years was less severely affected. He had the garlic odour, some somnolence later in the day, and a metallic taste but no anorexia, vomiting or constipation. He had no itch nor dry skin. He, too, had bluish-black patches on the skin but to a much lesser degree. Hospital admission for two days' investigation showed that full blood indices, liver function tests, renal function tests, blood electrolytes, urinalyses, and chest radiographs were all normal. The use of BAL (Amdur, 1947) and ascorbic acid (De Meio, 1947) in treatment was discussed but rejected as the former carries some risk (Amdur, 1947) and the latter merely removes the social disability of the garlic odour. Both patients made an uninterrupted recovery although the garlic smell took several weeks to clear.

\section{Discussion}

These cases demonstrate the classical symptoms and signs of tellurium intoxication (Shie and Deeds, 1920; Steinberg et al., 1942; Amdur, 1947), the most notable, constant, and early sign of tellurium absorption being the stench of sour garlic due to organic compounds of tellurium (eg, dimethyl telluride), which can be produced by microscopic amounts of tellurium. Reisert (1884) found that $0.5 \mu \mathrm{g}$ produced the garlic smell within $1 \frac{1}{4}$ hours and lasted 30 hours and the effect from the ingestion of $15 \mathrm{mg}$ lasted 237 days.

An interesting feature in these cases was the bluishblack skin discoloration on the face, neck, and webs of the fingers which has not previously been reported. In a review of the literature of tellurium and its compounds (Cerwenka and Cooper, 1961) no reference is made to bluish-black skin discoloration although they mention the discoloration of the mucosa of the ureter and bladder of the two fatal cases of Keall et al. (1946). Discoloration was also reported in the blood and internal organs of the experimental animals described by Gmelin and later by Hofmeister in the 19th century. The latter described the colour as indigo carmine and considered it to be due to the reducing action of tissue cells on the telluric compounds depositing elemental Te (Hofmeister, 1894). The two men described in this paper were handling volatile liquid esters which are readily absorbed through intact skin, possibly resulting in the deposition of elemental Te in the dermis and subcutaneous tissues. The streaky appearance of the face and neck lesions suggested contamination by rubbing or scratching, or direct exposure to the rising vapour. The papulovesicular 
eruption of the hands, arms, and neck of case 1 was thought by dermatologists to be a contact dermatitis and not directly due to tellurium. The patient started to wear rubber gloves after he noticed the discoloured patches between the fingers and may have developed a sensitivity reaction. However, the eruptions may have been precipitated by the ability of tellurium to inhibit sweating and produce itching and scaling of the skin. No specific therapy for systemic tellurium intoxication exists (Vignoli and Defretin, 1964; American Industrial Hygiene AssociationHygienic Guide Series, 1964). No treatment was attempted in these cases. Russian experimental research into the characteristics of tellurium as an industrial poison indicated that the dioxide in concentrations of $0.05 \mathrm{mg} /$ litre slows down growth rate in animals, reduces the haemoglobin and erythrocyte count, and upsets the normal ratio of serum protein fractions. Sandrackaja (1962) believes that, on the basis of its relationship to sulphur it acts as a poison, affecting particularly the liver and nervous system. Liver and renal function tests were normal in the two cases reported here and both patients made a spontaneous and complete recovery. No permanent damage resulted.

\section{References}

Amdur, M. L. (1947). Tellurium. Journal of Occupational Medicine, 3, 386-391.

American Industrial Hygiene Association-Hygienic Guide Series (1964). Tellurium. American Industrial
Hygiene Association Journal, 25, 198-201.

Cerwenka, E. A. and Cooper, W. C. (1961). Toxicology of selenium and tellurium and their compounds. Archives of Environmental Health, 3, 189-199.

De Meio, R. H. (1947). Tellurium, II. Effect of ascorbic acid on the tellurium breath. Journal of Industrial Hygiene and Toxicology, 29, 393-395.

Duckett, S. (1970). Fetal encephalopathy following ingestion of tellurium. Experientia, 26, 1239-1241.

Hofmeister, F. (1894). Ueber Methylierung im Thierkörper. Archives of Experimental Pathology and Pharmacology. 33, 198. (quoted by De Meio).

Keall, J. H. H., Martin, N. H., and Tunbridge, R. E. (1946). Three cases of accidental poisoning by sodium tellurite. British Journal of Industrial Medicine, 3, 175176.

Reisert, W. (1884). The so-called bismuth breath. American Journal of Pharmacology, 56, 177-180.

Sandrackaja, S. E. (1962). Experimental research into the characteristics of tellurium as an industrial poison. Gigiena Truda $i$ Professional 'nye Žabolevanija, 6, no. 2, 44-50.

Shie, M. D. and Deeds, F. E. (1920). The importance of tellurium as a health hazard in industry. Public Health Reports, 35, 939-942.

Steinberg, H. H., Massari, S. C., Miner, A. C., and Rink, R. (1942). Industrial exposure to tellurium. Journal of Industrial Hygiene and Toxicology, 24, 183192.

Vignoli, L. and Defretin, J. P. (1964). La toxicologie du tellure. Annales de Biologie Clinique, 22, 399-417.

Received for publication 1 April 1974

Accepted for publication 13 August 1974 